Campos Neutrais - Revista Latino-Americana de Relações Internacionais Vol. 2, No 1, Janeiro- Abril de 2020. Santa Vitória do Palmar - RS.

\title{
2020 breve e devastador
}

\section{Hemerson Luiz Pase*}

A COVID-19 colocou 2020 na história como o primeiro ano de drásticas e rápidas transformações, no mundo, no século XXI. Por este motivo, 2020 será lembrado como 1917, com a primeira guerra mundial e, 1945, como a segunda, ou seja, como um ano marcado por mortes, degradação política e destruição econômica. São conhecidas outras grandes epidemias, como a da Peste Negra (1347 - 1351), a Gripe Espanhola (1918 1920), não obstante, nenhuma delas foi tão pandêmica quanto será a COVID-19. '

Nenhum entusiasta da globalização da economia considerava, com seriedade, os riscos sanitários de um mundo conectado, onde mercadorias e pessoas se deslocassem com facilidade e rapidez, chegando a atravessar o planeta, em algumas horas. Aliás, essa situação somente foi contada em forma de utopia, pelo cinema.

A COVID-19 também ataca a economia, já que a ausência de uma vacina efetiva impõe o isolamento e distanciamento social e, algumas vezes, o confinamento, como a medida preventiva mais adequada para evitar a contaminação e a morbidade. Esse ataque produz, ainda, externalidades, entre as quais pode-se citar a mais vigorosa: a "mão invisível do mercado". Isso porque, não há respostas para situações como essas, pois o Estado que é chamado a construir hospitais e financiar pesquisas para desenvolver uma vacina.

A economia internacional e as relações internacionais sentiram um evidente retrocesso e os governos nacionais têm realizado ações, muitas vezes, desencontradas e pouco articuladas. Alguns governos mais responsáveis não têm se constrangido em fechar as fronteiras, enquanto outros confiscam víveres de parceiros comerciais. Em poucos momentos de ausência de guerra, se percebeu a necessidade da existência e do empoderamento de uma agência internacional, como ocorre com a Organização Mundial da Saúde (OMS).

Nos países democráticos, onde a teoria do neoliberalismo logrou sucesso, no início do século XXI, encontrou-se dificuldade para lidar com a Pandemia, seja em razão da configuração interna Federalista, como são Brasil e Estados Unidos, seja por falta de recursos ou de capacidade para implementar políticas públicas. É neste ambiente embebido

\footnotetext{
${ }^{*}$ Doutor em Ciência Política. Professor do Curso de Graduação em Relações Internacionais e do Programa de Pós-Graduação em Direito e Justiça Social da Universidade Federal do Rio Grande (FURG). Editor da Revista Latino-Americana de Relações Internacionais - Campos Neutrais. E-mail: hemerson.pase@gmail.com
} 
Campos Neutrais - Revista Latino-Americana de Relações Internacionais Vol. 2, $\mathrm{N}^{\mathrm{O}}$ 1, Janeiro- Abril de 2020. Santa Vitória do Palmar - RS.

em incerteza e preocupação, que temos a honra de apresentar o Número 1, do Volume 2, da Campos Neutrais: Revista Latino-Americana de Relações Internacionais.

Este número conta com cinco artigos de alto nível acadêmico. Os dois primeiros têm como objeto central as políticas públicas para pessoas com deficiência. No primeiro, Políticas públicas e direitos das pessoas com deficiência no Brasil (1988-2016), Alfredo Gugliano trata de questões relacionadas à integração social de pessoas com deficiência, um grupo ainda excluído das principais democracias ocidentais, que ainda, hoje, tem direitos básicos desconsiderados por diversos Estados, mantidos em silêncio em campanhas e programas eleitorais. A partir do caso brasileiro, o artigo analisa o desenvolvimento de políticas públicas voltadas para pessoas com deficiência no país, destacando alguns avanços importantes.

No segundo artigo, $\mathrm{O}$ bem-estar social e as políticas públicas destinadas à inclusão das pessoas com deficiência no mercado de trabalho no Brasil e em Portugal, Marcia L. Borges, Danieli V. Moura, Ana Paula D. Patella, Caricia H. A. O. dos Santos e Manuela M. Parada comparam as políticas públicas de inclusão, no mercado de trabalho de pessoas, com deficiência, entre Portugal e no Brasil. As autoras exploram o tema, a partir da hipótese de que, em ambos os países, o Estado transferiu a responsabilidade da inclusão da pessoa com deficiência, no mercado de trabalho, à sociedade civil, ficando a ação estatal restrita à fiscalização. A semelhança entre os países é a prevalência da concepção da deficiência como problema individual e familiar, cabendo ao Estado a fiscalização.

No terceiro texto, Decolonialidade e futebol: a quebra da lógica periferiacentro, Juliano O. Pizarro, Carmem S. M. Rial e Luis C. Rigo afirmam que o processo de colonização não se encerrou com as independências dos países, pois a teoria neoliberal, propagada como caminho único, pelo processo de globalização econômica, manteve a lógica da colonialidade. No artigo, a autora e os autores discutem o papel do futebol nesse processo, ou seja, como o esporte mais praticado do mundo, apesar de mostrar as facetas mais preconceituosas da sociedade e a lógica colonial, é um instrumento extremamente importante no processo decolonial, fazendo com que se quebre a lógica periferia-centro, tradicional do atual sistema-mundo.

O quarto artigo, escrito por Matheus Muller e Jennifer A. Morais, intitulado O Poder Judiciário e a política de privatização do setor elétrico brasileiro objetiva verificar a atuação do Poder Judiciário brasileiro, no processo de privatização de empresas estatais, do setor elétrico, efetivado na década de 1990 e iniciado nos anos 2000. O autor e a autora mostram que, nesse período, 26 empresas foram leiloadas para a iniciativa 
Campos Neutrais - Revista Latino-Americana de Relações Internacionais Vol. 2, No 1, Janeiro- Abril de 2020. Santa Vitória do Palmar - RS.

privada, fazendo do segmento elétrico o que mais contribuiu ao Programa Nacional de Desestatização - PND, no âmbito do maior processo de transferência de patrimônio estatal no mundo. $\mathrm{O}$ artigo mostra que o papel das decisões do Judiciário, na política de privatização do setor elétrico nacional, não é de freio.

No último artigo, Vulnerabilidades sociais expostas pela Covid-19 no Brasil, Mónica Montana, Mateus A. M. da Silva e Mylena de A. Melo mostram como o surgimento da Covid-19 é responsável pelas mais severas e repentinas mudanças globais e individuais das últimas décadas, trazendo à tona a grave crise preexistente nas políticas públicas de saúde. Neste sentido, as autoras e o autor se propõem a discutir, no âmbito brasileiro, a ligação existente entre a composição da carta magna, com a manutenção das desigualdades sociais, as quais ficaram em evidência, mediante a falta de infraestrutura física e humana para atender, com celeridade e assertividade, às exigências da pandemia atual, ocasionada pelo Covid-19.

Nos próximos números, pretendemos apresentar mais artigos que problematizem a pandemia, as ciências humanas e as relações internacionais.

Desejamos boa leitura e muita saúde! 